\title{
Aptidão climática do sorgo como suporte alimentar a avicultura de São Bento Una - Pernambuco, Brasil
}

\author{
Manoel Vieira de França* ${ }^{a *}$ Raimundo Mainar de Medeiros ${ }^{\mathrm{a}} \odot$ \\ a Universidade Federal Rural de Pernambuco, Brasil \\ *Autor correspondente (manoelvieiraufrpepesquisa@gmail.com)
}

\section{N F O}

\section{Keywords}

agricultural cultivars irrigation climate variables

\section{Palavras-chaves} cultivares agrícolas irrigação

variáveis climáticas

\begin{abstract}
A B S T R A C T
Sorgo climate fitness as a support to feed the São Bento Una beekeeping - Pernambuco, Brazil

Carry out the agroclimatic aptitude that allows the identification of the productive potential of the sorghum cultivar for São Bento do Una, as food support for poultry, based on the climate identifiers established according to the requirement of the crop under study. The rainfall data were obtained from the Northeast Development Superintendence and from the Pernambuco Water and Climate Agency from 1920 to 2018. The monthly and annual temperature data used correspond to the same period of the historical rainfall series, the thermal indices were estimated. Estima_T software. They applied statistically simplified calculations to define mean. After statistical applications, water balance and evapopluviogram graphs were generated. The technique of classification and climatic aptitude used the deficiency indexes, surplus water and rain for the study area which indicates a moderate aptitude for the sorghum planting. This planting should be carried out in the rainy season, using soil preparation techniques and assisting where possible with additional irrigation when required. To avoid problems with soil moisture and the plantation does not suffer water stress caused by prolonged summer periods, low areas should be chosen for planting.
\end{abstract}

\section{R E S U M O}

Realizar a aptidão agroclimática que permita identificar o potencial produtivo do cultivar sorgo para São Bento do Una, como suporte alimentar a avicultura tomando-se com base os identificadores do clima estabelecidos conforme a exigência da cultura em estudo. Os dados pluviométricos foram adquiridos da Superintendência do Desenvolvimento do Nordeste e da Agência Pernambucana de Água e Clima compreendido entre os anos de 1920 a 2018. Os dados de temperatura mensal e anual utilizados correspondem ao mesmo período das séries históricas pluvial, os índices térmicos foram estimados pelo software Estima_T. Aplicaram os cálculos simplificados estatisticamente para definir, média. Após as aplicações estatísticas geraram-se os gráficos do balanço hídrico e do evapopluviograma. A técnica de classificação e aptidão climática utilizou-se dos índices de deficiência, excedentes hídricos e pluviais para a área em estudo a qual aponta uma aptidão moderada para o plantio do sorgo. Este plantio deverá ser realizado no período chuvoso, utilizando-se das técnicas do preparo do solo e a ajuda quando possível das irrigações suplementares quando exigidos. Para evitar-se problema com umidade de solo e a plantação não sofre estresse hídrico ocasionado por períodos de veranicos prolongados deve-se escolher áreas de baixos para realizações do plantio. 


\section{INTRODUÇÃO}

A avicultura consiste na prática de produção de frangos para comercialização. Considerando o aumento da avicultura e a realidade que o setor vivencia no momento, surge o interesse de realizar o trabalho sobre esta atividade, em que muitos produtores rurais estão ingressando.

O setor avícola brasileiro tem uma participação importante entre os produtores mundiais e o pequeno produtor que ingressa na atividade, tem demonstrado satisfação e busca melhorias e adequações para atender a demanda mundial, estadual, regional e local. A participação da avicultura no agronegócio mostra uma perspectiva de continuar em ritmo de crescimento nos próximos anos.

A temperatura média, precipitação, umidade relativa do ar e evaporação estão relacionadas à agricultura por sua importância junto aos processos climáticos insolação os quais são alvo de pesquisas especialmente. São os elementos meteorológicos que exercem influência direta sobre as condições agrícolas e avicultura (Amorim et al., 2004). O município de São Bento do Uma (PE) se destaca dos demais municípios pelo potencial da produção avícola dentro do estado e os parâmetros em discussões devem serem levados em considerações para que os avicultores realizem melhores planejamento.

Segundo Desouzart (2012) o aumento no consumo de carne de frango o setor do agronegócio vem aumentou sua produção e sendo considerado atualmente como o setor mais importante para o agronegócio brasileiro e em especial em São Bento do Una. De acordo ainda com o autor a avicultura surge como uma atividade que visa gerar o desenvolvimento do pequeno produtor por meio de sua produção. A aplicabilidade de novas tecnologias propicia um desenvolvimento e modernização da atividade, mas isto requer altos custos de investimentos, sendo geralmente estes conseguidos por financiamentos bancários por intermédio de projetos das agroindústrias.

A aptidão climática destina-se a caracterizar os fatores meteorológicos que mais agem no desempenho dos cultivos que em suas condições extremas, possam a prejudicar sensivelmente o seu crescimento e desenvolvimento das cultivares.

A precipitação da região Nordeste (NEB) constitui variável importante do clima, com reflexos na plantação agrícola. Portanto, é essencial a identificação de áreas e períodos críticos para cultivos e menor risco à agricultura, tendo em vista que através do uso de consideráveis volumes de água, podem-se obter produções economicamente viáveis, uma vez sendo atendidas às exigências hídricas nos estágios de maior necessidade, principalmente nos períodos críticos da cultura segundo a afirmação de
Oliveira (1996).

O NEB se caracteriza pela irregularidade espacial e temporal pluvial e dos processos de escoamento e erosão dos solos, como também pelo alto potencial para evaporação da água em desempenho da enorme disponibilidade de energia solar e das altas temperaturas durante o ano. Assim, a região do NEB é considerada como região anômala no que se refere à distribuição espacial e temporal da precipitação ao longo do ano. Souza et al. (1998). Os climas tropicais quentes e úmidos, como o nosso, parece ser o mais desfavorável, e o homem branco não pode viver por muito tempo em tais climas sem que sofra desgaste de energia e de resistência às doenças.

O conhecimento do comportamento das variáveis climáticas é de súmula importância para a idealização das atividades agrícolas. A temperatura destaca-se na condução de estudos concernentes à ordenação agrícola, uso do solo, zoneamento ecológico e aptidão climática, época de semeadura, estimativa do ciclo dos cultivos, dentre outros informes Oliveira Neto et al. (2002).

Assegurando de melhor produtividade das culturas, e em determinados caso sendo indispensável o uso da irrigação em regiões que proporcionam grandes deficiências hídricas limitando o desenvolvimento das culturas, principalmente quando esta deficiência estende por todo ano. Santos et al. (2010).

A compreensão dos fatores agroclimáticos de determinada área poderá auxiliar nas atividades humanas desenvolvidas, com principal importância na agricultura. A aplicação do balanço hídrico como instrumento de manejo, procura conduzir ações de planejamento na plantação agrícola para a área estudada, visando maiores rentabilidade dos cultivos assim como reduzir os riscos de degradação do ambiente.

O sorgo é uma planta de origem tropical, de dias curtos e com altas taxas fotossintéticas, exigindo, um clima quente para poder expressar seu potencial de produção, MAPA (2014). Nas semeaduras tardias e nos cultivos após uma safra de verão a produtividade do sorgo é grandemente afetada pelo regime das chuvas, limitações de radiação solar e sobre as influências das temperaturas baixas durante o final do ciclo (MAPA, 2014). A cultura, com características xerófilas, é considerada tolerante a períodos secos, notadamente em regiões do NEB segundo a citação de Tabosa et al. (2002).

Por pertencer ao grupo de plantas $\mathrm{C}_{4}$, o sorgo suporta elevados níveis de radiação solar, respondendo com altas taxas fotossintéticas, minimizando a abertura dos estômatos e consequente perda d'água. Assim, o aumento da intensidade luminosa implica em maior produtividade, sempre que as 
demais condições sejam favoráveis. EMBRAPA, (2012).

O cultivo do sorgo exige de 300 a $400 \mathrm{~mm}$ de precipitação, distribuídos regularmente durante o seu ciclo de crescimento e desenvolvimento com o intuito de alcança produtividade satisfatórios, sem a necessidade de irrigação suplementar. A cultura tolera ocorrências de deficiência hídrica, inclusive pequenos veranicos, sendo considerada resistente à seca. As fases fenológicas críticas da cultura correspondem ao estádio de plântula e no florescimento, sendo importante nessas épocas um apropriado nível de fornecimento d'água para uma apropriada produção (Tabosa et al., 2002; EMBRAPA, 2012).

Para o incremento das culturas é necessário o uso adequado d'água, o déficit ou o excesso hídrico podem influenciar na plantação de uma determinada localidade agrícola. Bergamaschi et al. (2004), verificaram que a produtividade de culturas agrícolas é fortemente dependente das precipitações, sobretudo quando se trata de cultura de sequeiro, o déficit ou excesso hídrico pode comprometer o preparo do solo, e toda a sua cadeia produtiva.

Medeiros et al. (2013) demostraram que a aplicabilidade do método do balanço hídrico, que abastece o saldo de água no solo para o vegetal, e contabiliza-se a precipitação ou irrigação e a evapotranspiração (ETP), através do uso da capacidade de água do solo, realizaram o computo do balanço hídrico da localidade. A ETP informa o quanto de umidade está sendo perdida pela planta através da transpiração e da evaporação do solo, logo se torna parâmetro importante na determinação da necessidade hídrica da planta, Ferreira (2014).

Medeiros et al. (2015) caracterizaram o clima e concretizaram o zoneamento agroclimático de onze cultivares assinalando as aceitáveis aptidões para o município de Barbalha - CE. Utilizaram-se da série de precipitação e temperatura média para a efetivação do computo do balanço hídrico, classificação climática, construção do evapopluviograma e o zoneamento agroclimático das referidas culturas. Estabeleceram que a região estudada apresentasse aptidão plena para as cultivares: abacaxi, algodão herbáceo, feijão, mamona, mandioca e sisal. Para as culturas: caju, milho e sorgo, contatou-se aptidão moderada. Apenas o cultivo da banana e cana-deaçúcar foi restrito devido o grande déficit hídrico da área.

Medeiros et al. (2020) mostraram em seus estudos que os fatores climáticos, balanço hídrico e classificação climática para o cultivo do caju verso sorgo utilizando-se do método de Thornthwaite e Mather (1948, 1955), para o município do Recife. A técnica de classificação e aptidões climática utilizando dos índices de deficiência hídricas para o município de Recife não fornecem subsídios de alta confiabilidade para o estudo. A determinação dos componentes do balanço hídrico permitiu um maior conhecimento da realidade climática da área estudada, ao mesmo tempo em que oferece condições de compatibilização entre a água retida no solo e as diferentes formas de utilização do mesmo, objetivando a minimização dos riscos para a agropecuária e para as populações.

Medeiros (2020) avaliou a aptidão agroclimática dos cultivos milhos e sorgos que permita visualizar ou identificar o seu potencial produtivo no estado da Paraíba. A aptidão plena da cultivar milho esta localizada no setor litoral e agreste. Na região Cariri/Curimatau e parte da região do sertão tem-se aptidão restrita por deficiências hídricas. A aptidão moderada ocorreu na parte do cariri/curimatau e alto sertão. A aptidão climática para a cultura do sorgo plena sem restrições localiza-se na região litorânea e área isolada no Cariri/Curimatau. A aptidão plena com período chuvoso prolongado situase no agreste e em área isolado do alto sertão.

Wollmann et al. (2013) descreveram que as categorias hídricas e clima, são proeminentes em atendimento ao zoneamento agroclimático, tendendo à monopólio de culturas de maneira econômica e rentáveis. Estes são os atributos agroclimáticos que motivam a aptidão dos desenvolvimentos das culturas em determinada área.

Toledo et al. (2009) mostraram que a aptidão climática de uma área é determinada com apoio na agregação dos índices pluviais, térmicos e da altitude local, sendo de grande importância sob o aspecto própria das culturas, causadora de recursos na agricultura.

$\mathrm{O}$ estudo da variabilidade espaço-temporal de longas séries meteorológicas, além de contribuir indicando quais as áreas mais propícias ao plantio/semeadura de culturas, indica também os períodos, além de trazer informações extremamente importantes sobre possíveis descontinuidades climáticas, tendências ou periodicidades, auxiliando o estudo das forcantes moduladoras das condições meteorológicas em uma região conforme Blain (2009).

Realizar a aptidão agroclimática que permita identificar o potencial produtivo do cultivar sorgo no município de São Bento do Una, como suporte alimentar a avicultura tomando-se como base os indicadores do clima estabelecidos conforme a exigência da cultura para a área estudada.

\section{MATERIAL E MÉTODOS}

São Bento do Una localiza-se na mesorregião do Agreste e na Microrregião do Vale do Ipojuca do Estado de Pernambuco, A sede do município tem altitude de 614 metros e coordenadas geográficas 
de $08^{\circ} 31^{\prime} 22^{\prime \prime}$ de latitude sul e $36^{\circ} 06^{\prime} 40^{\prime \prime}$ de longitude oeste. Com população estimada de 58.251 habitantes com densidade demográfica de 74,03 $\mathrm{hab} / \mathrm{km}^{2}$. Limitando-se ao norte com Belo Jardim, sul com Jucati, Jupi e Lajedo, leste com Cachoeirinha, a oeste com Capoeiras, Sanharó e Pesqueira. A área municipal é de $719,15 \mathrm{~km}^{2}$.

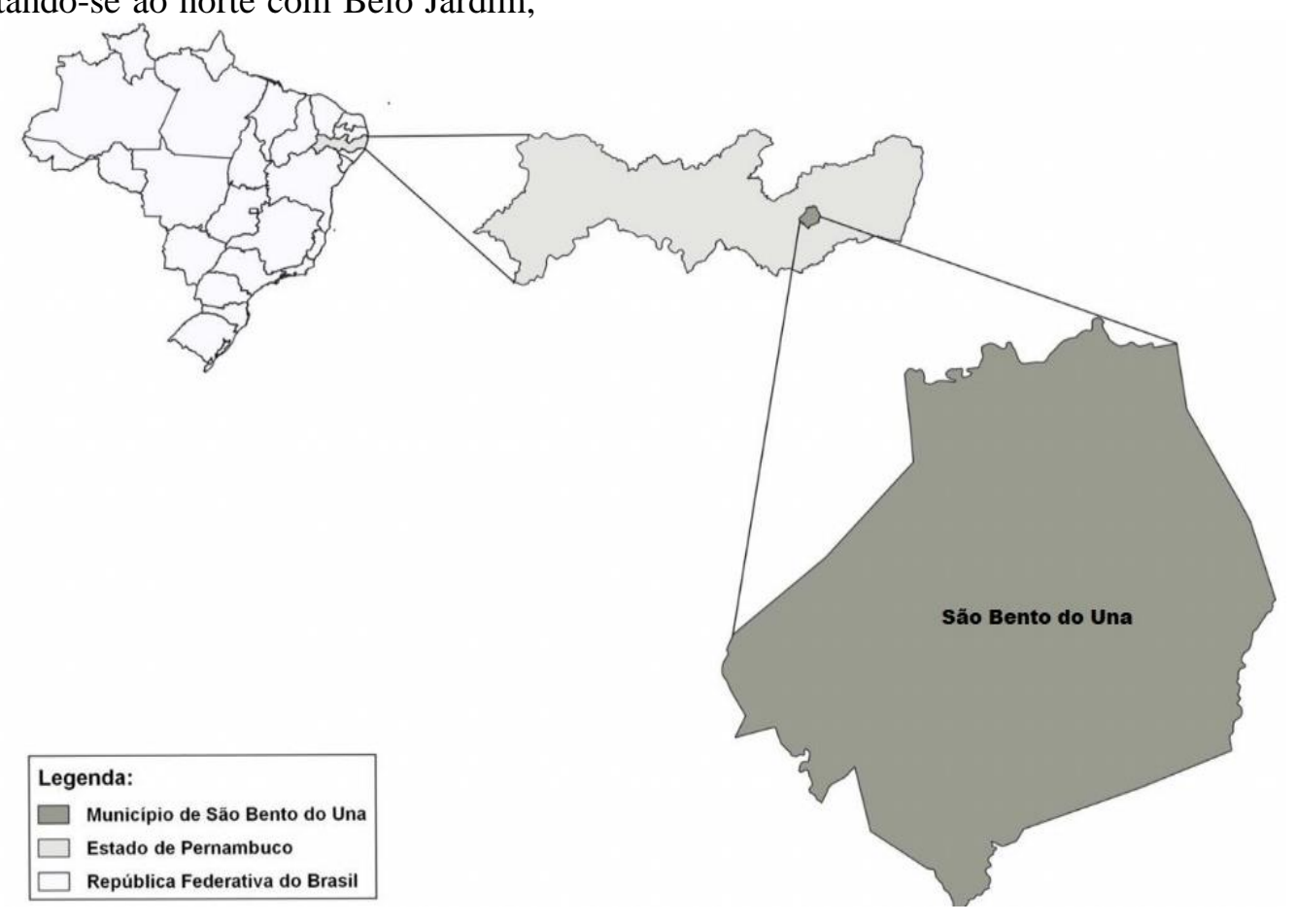

Fonte: Adaptado de Medeiros (2020).

Figura 1 - Localização da área de estudo no estado do Pernambuco.

A classificação de Köppen (1928, 1931) para São Bento do Una gerou o tipo de clima "As" (Tropical Chuvoso, com verão seco), esta classificação está em conformidades com os estudos dos autores Medeiros et al. (2018) e Alvares et al. (2014). O clima caracteriza-se por temperaturas médias elevadas $\left(22\right.$ a $\left.30^{\circ} \mathrm{C}\right)$ e uma amplitude térmica anual muito pequena, em desempenho a baixa latitude e elevação $(<700 \mathrm{~m})$ segundo Varejão-Silva et al. (1984).

O período chuvoso se inicia em fevereiro com chuvas de pré-estação (chuvas que ocorrem antes da quadra chuvosa) com seu término ocorrendo no final do mês de agosto e em alguns anos isolados se prolonga até a primeira quinzena do mês de setembro. O trimestre chuvoso (maio, junho e julho) e os meses seco entre outubro e dezembro. Os fatores provocadores de chuvas no município são a contribuição da Zona de Convergência Intertropical (ZCIT), formação dos vórtices ciclônicos de altos níveis (VCAS), contribuição dos ventos alísios de nordeste no transporte de vapor e umidade a quais condensam e forma nuvens provocando chuvas de moderadas a fortes, formações das linhas de instabilidades, orografia e suas contribuições local e regional formando nuvens e provocando chuvas. Medeiros (2016).

Os dados pluviométricos foram adquiridos da
Superintendência do Desenvolvimento do Nordeste (SUDENE, 1990), Agência Pernambucana de Água e Clima (APAC, 2019) compreendido entre os anos de 1920 a 2018. Valeu-se dos cálculos simplificados estatisticamente para definir, média, desvio padrão, coeficiente de variância, máximos e mínimos valores absolutos ocorridos, definiu-se o período chuvoso e seco. Após as aplicações estatísticas geraram-se os gráficos do balanço hídrico e do evapopluviograma.

Os dados de temperatura média utilizados correspondem aos das séries históricas de 1920 - 2018. Para análise dos dados foi utilizado um programa em planilha eletrônica. Utilizaram-se valores da temperatura do ar estimadas pelo software Estima_T (Cavalcanti et al. 1994; 2006) no período de 1962-2018 expressa pela seguinte equação:

$$
\begin{gathered}
\mathrm{T}=\mathrm{C}_{0}+\mathrm{C}_{1} \lambda+\mathrm{C}_{2} \varnothing+\mathrm{C}_{3} \mathrm{~h}+\mathrm{C}_{4} \lambda^{2}+\mathrm{C}_{5} \emptyset^{2}+\mathrm{C}_{6} \mathrm{~h}^{2}+ \\
\mathrm{C}_{7} \lambda \emptyset+\mathrm{C}_{8} \lambda \mathrm{h}+\mathrm{C}_{9} \varnothing \mathrm{h}
\end{gathered}
$$

Onde:

$\mathrm{C}_{0}, \mathrm{C}_{1}, \ldots ., \mathrm{C}_{9}$ são as constantes;

$\lambda, \lambda^{2}, \lambda \emptyset, \lambda \mathrm{h}$ longitude;

$\varnothing, \varnothing^{2}, \lambda \varnothing$ latitude;

$\mathrm{h}, \mathrm{h}^{2}, \lambda \mathrm{h}, \varnothing \mathrm{h}$ altura.

Também estimaram a série temporal de 
temperatura, adicionando a esta à anomalia de temperatura do Oceano Atlântico Tropical (Silva et al., 2006).

$$
\mathrm{T}_{\mathrm{ij}}=\mathrm{T}_{\mathrm{i}}+\mathrm{AAT}_{\mathrm{ij}} \quad \mathrm{i}=1,2,3, \ldots, 12 \quad \mathrm{j}=1950
$$

Onde

$$
\begin{aligned}
& i=1,2,3, \ldots, 12 \\
& j=1950,1951,1952,1953, \ldots, 2017 .
\end{aligned}
$$

As falhas de dados entre a década de 90 pode ser explicada pela troca de responsabilidade na coleta dos registros pluviais da antiga (SUDENE, 1990) para o (Lamepe, 1990) neste período de transição as estações passaram por manutenção e outras foram implantadas em algumas cidades dentre $1989 \mathrm{e}$ 1992. Para tanto foram realizados preenchimentos de falhas, homogeneização e consistência nos referidos dados para pode-se trabalhar e fornecer informações confiáveis ao público em geral. Os dados falhos foram preenchidos com os dados de três postos vizinhos, localizados o mais próximo possível, onde se aplicou a seguinte forma:

$$
P x=\frac{1}{3}\left(\frac{N x}{N a} P a+\frac{N x}{N b} P b+\frac{N x}{N c} P c\right)
$$

Em que:
Px é o valor de chuva que se deseja determinar;

Nx é a precipitação diária do posto $\mathrm{x}$;

NA, NB e NC são, respectivamente, as precipitações diárias observadas dos postos vizinhos A, B e C;

PA, PB e PC são, respectivamente, as precipitações observadas no instante que $\mathrm{o}$ posto $\mathrm{x}$ falhou.

$\mathrm{Na}$ obtenção do computo do balanço hídrico (BH) utilizou-se do método de Thornthwaite e Mather $(1948,1955)$, com preparação de planilhas eletrônicas realizadas por Medeiros (2016) o qual contabiliza a água do solo, onde a chuva representa o ganho e a ETP a perda de umidade do solo, estimando-se os valores dos Excedentes Hídricos (EXC) e Deficiência Hídrica (DEF). Com base na capacidade de água disponível no solo (CAD) de $100 \mathrm{~mm}$.

Para a avaliação de aptidão climática da cultura do sorgo, foram utilizados os critérios conforme a metodologia adaptada da Empresa Brasileira de Pesquisa Agrícola (EMBRAPA, 2012), em que foram realizadas simulações de balanço hídrico sequencial que permitiu uma visão da influência da

\begin{tabular}{|c|c|c|c|c|}
\hline Aptidão climática & $\mathbf{E X C}(\mathbf{m m})$ & DEF (mm) & PREC/ETP (mm) & PREC (mm) \\
\hline $\mathrm{C}_{3}-$ Moderada por excesso hídrico & $\geq 300$ & & & $\geq 600$ \\
\hline $\begin{array}{l}\mathrm{C}_{2}-\text { Plena com período chuvoso prolon- } \\
\text { gado }\end{array}$ & $200<\mathrm{EXC}_{\mathrm{j}} \leq 300$ & & $\mathrm{PREC}_{4} / \mathrm{ETP}_{4} \geq 1$ & $500<$ PREC $\leq 600$ \\
\hline$C_{1}$ - Plena sem restrição & $0<\mathrm{EXC}_{\mathrm{j}} \leq 200$ & $\mathrm{DEF}_{\mathrm{j}}<10$ & $\mathrm{PREC}_{4} / \mathrm{ETP}_{4}<1$ & $400<$ PREC $\leq 500$ \\
\hline $\mathrm{C}_{4}-$ Moderada por deficiência hídrica & & $\mathrm{DEF}_{\mathrm{j}}<20$ & $\mathrm{PREC}_{4} / \mathrm{ETP}_{4}<1$ & $280<$ PREC $\leq 400$ \\
\hline $\begin{array}{l}\mathrm{C}_{5}-\text { Inapta por deficiência hídrica acen- } \\
\text { tuada }\end{array}$ & & $\mathrm{DEF}_{\mathrm{j}} \geq 20$ & & $<280$ \\
\hline
\end{tabular}
deficiência e do excesso hídrico do plantio à colheita, mediante aos parâmetros adotados. (Tabela $1)$.

Tabela 1 - Critérios utilizados na avaliação de aptidão climática da cultura do sorgo.

Fonte: Adaptado EMBRAPA (2012).

Legenda: EXC = Excedente hídrico; DEF = Deficiência hídrica; PREC/ETP = Precipitação/Evapotranspiração; Prec $=$ Precipitação.

\section{RESULTADOS E DISCUSSÃO}

O resultado do computo do $\mathrm{BH}$ no período 19202018 esta mostrado na tabela 2. Avaliando CAD $100 \mathrm{~mm}$. A quantidade d'água evapotranspirada é expressa pela evapotranspiração, assim como a evaporação que se comportaram de forma irregular à distribuição pluvial. Ainda segundo o computo do BHC determinou-se os índices: aridez, umidade e hídrico e CV, onde o CV é a concentração da evapotranspiração potencial na estação quente, determinada pelos três meses consecutivos de temperatura mais elevada do ano (trimestre mais quente). Tais índices determinam a classificação climática, baseada em observações e estudos proposto por Thornthwaite $(1948,1955)$.

A limitação dos recursos hídricos na atualidade é importante condicionante ao desenvolvimento socioeconômico, acarretando inúmeras provocações ao planejamento e gerenciamento deste recurso (Sousa et al., 2015). 
Tabela 2 - Balanço hídrico climatológico do município São Bento do Una - PE.

\begin{tabular}{c|c|c|c|c|c|c}
\hline Meses & $\mathbf{T}\left({ }^{\circ} \mathbf{C}\right)$ & $\mathbf{P}(\mathbf{m m})$ & $\mathbf{E T P}(\mathbf{m m})$ & $\mathbf{E V R}(\mathbf{m m})$ & $\mathbf{D E F}(\mathbf{m m})$ & $\mathbf{E X C}(\mathbf{m m})$ \\
\hline Jan & 23,5 & 40,0 & 104,8 & 40,1 & 64,7 & 0,0 \\
Fev & 23,4 & 53,4 & 96,2 & 53,5 & 42,7 & 0,0 \\
Mar & 23,2 & 91,8 & 102,3 & 91,9 & 10,4 & 0,0 \\
Abr & 22,8 & 84,0 & 92,9 & 84,0 & 8,9 & 0,0 \\
Mai & 21,6 & 81,7 & 82,1 & 81,7 & 0,4 & 0,0 \\
Jun & 20,4 & 74,5 & 67,6 & 67,6 & 0,0 & 0,0 \\
Jul & 19,5 & 64,3 & 62,5 & 62,5 & 0,0 & 0,0 \\
Ago & 19,7 & 33,4 & 64,6 & 35,7 & 28,8 & 0,0 \\
Set & 20,8 & 20,1 & 73,1 & 22,7 & 50,4 & 0,0 \\
Out & 22,3 & 19,4 & 92,0 & 21,4 & 70,7 & 0,0 \\
Nov & 23,2 & 21,1 & 99,7 & 22,1 & 77,6 & 0,0 \\
Dez & 23,5 & 24,5 & 108,0 & 25,0 & 83,0 & 0,0 \\
\hline Anual & 22,0 & 608,2 & 1045,9 & 608,2 & 437,6 & 0,0 \\
\hline
\end{tabular}

Legenda: Temperatura do ar média (T), Precipitação (P), Evapotranspiração potencial (ETP), Evaporação real (EVR), Deficiência hídrica (DEF) e Excedente hídrico (EXC).

A temperatura média do ar oscila $19,5^{\circ} \mathrm{C}$ no mês de julho a $23,5^{\circ} \mathrm{C}$ no mês de dezembro, janeiro com temperatura anual de $22{ }^{\circ} \mathrm{C}$. O índice pluvial anual foi de $608,2 \mathrm{~mm}$, o quadrimestre chuvoso centrase nos meses de março a junho, representando $54,6 \%$ da precipitação anual, o quadrimestre seco ocorre nos meses de setembro a outubro fluindo entre 19,4 mm.mês ${ }^{-1}$ a 24,5 mm.mês $\mathrm{s}^{-1}$, representando $14 \%$ do total anual pluvial.

A evapotranspiração anual de $1045,9 \mathrm{~mm}$, as flutuações mensais da ETP oscilam entre $62,5 \mathrm{~mm}$ no mês de julho a 104,8 mm no mês de janeiro. Evapotranspirou $72 \%$ acima dos índices pluviais. A EVR anual foi de 608,2 mm igualando-se aos índices pluviais. As flutuações mensais da EVR oscilaram entre $21,4 \mathrm{~mm}$ no mês de outubro a $91,9 \mathrm{~mm}$ no mês de março.

As deficiências hídricas foram registradas nos meses de agosto a abril com valor anual de 437,6 mm, não se registrou excedentes hídricos durante o ano. O município estudado apresentou os respectivos valores para os índices de: umidade de $41,84 \%$, Aridez com $0,42 \%$ e o hídrico com $-0,25 \%$.

As flutuações da deficiência hídrica devem ser observadas atenciosamente no planejamento agropecuário, apontando para uma agricultura segura e economicamente viável, onde se recomenda o uso de sistemas de irrigação para os meses de maiores deficiências os quais irá garantir produtividade em quantidade e qualidade das culturas (Santos et al., 2010). As informações climáticas são de fundamentais importância para elaborar um planejamento dos cultivos e o seu manejo durante o ciclo das culturas, destacando-se as variabilidades dos índices pluviais e a intensidade da ETP, podendo ser evitado, ou, reduzindo ao máximo, a ocorrência de déficit hídrico, Marengo et al. (2004).

\section{Reposição Retirada Excedente $\square$ Deficiência}

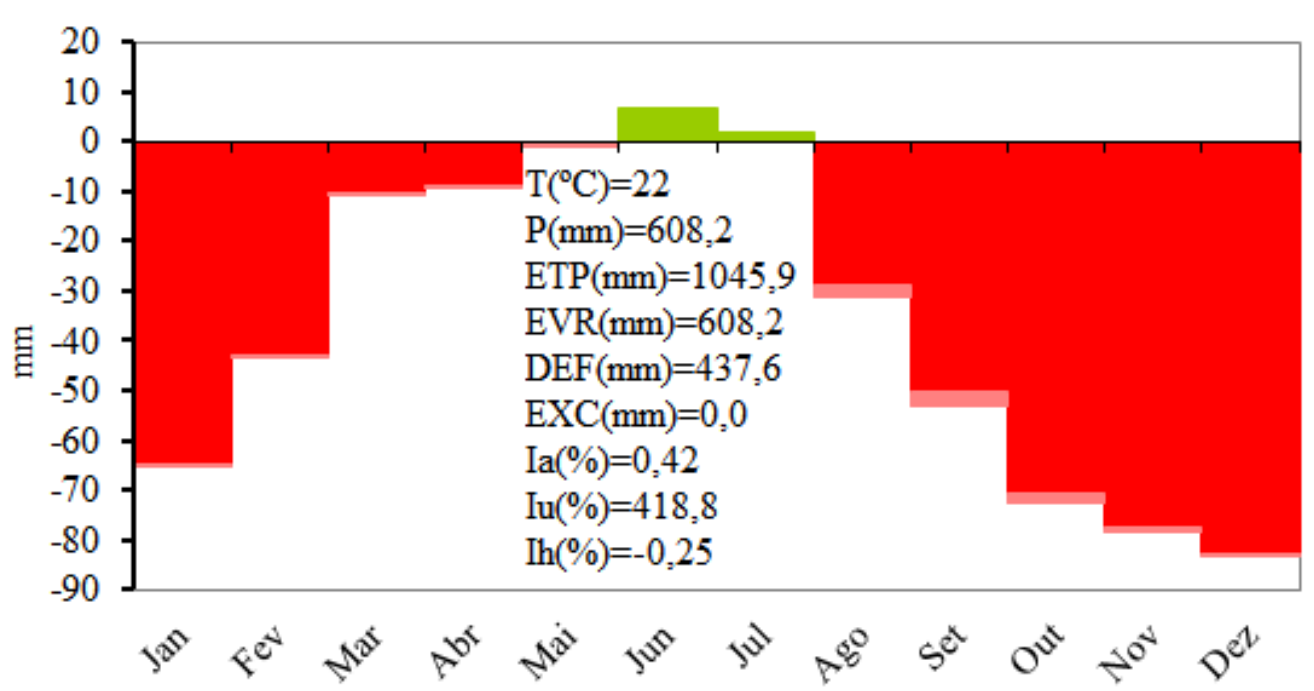

Figura 2 - Representação gráfica do balanço hídrico climatológico para o município de São Bento do Una PE, no período 1920 - 2018. 
A figura 2 ilustra o resultado da contabilidade hídrica para a área municipal de São Bento do Una no período 1920 - 2018. A predominância das deficiências hídricas registrou-se entre agosto a abril. Não se registrou excedentes hídricos, a reposição d'água no solo registrou-se de junho e julho, a retirada observa-se entre os meses de março a dezembro. O estudo de Medeiros (2018) e do IPCC (2014) corroboram com os resultados do trabalho em discussões.

A variabilidade das oscilações entre as quadras seca e chuvosa de cada localidade, e as oscilações dos fatores provocadores e/ou inibidores de chuvas depende exclusivamente de sistemas de meso, grande e micro escala, auxiliados pelas contribuições dos efeitos locais e/ou regionais, da orografia e do posicionamento da Zona de convergência Intertropical, a atuação dos Vórtices Ciclônico de Altos Níveis, os Distúrbios Ondulatórios de Leste, troca de calor sensível por calor latente e vice-versa entre diversos fatores que auxiliam as flutuações pluviais. Medeiros (2016).

Utilizando-se dos resultados do BHC e da contribuição entre a ETP e os índices pluviais e elaborou-se o evapopluviograma Figura 03, visando a efetivação do zoneamento agroclimático da cultura estudada em São Bento do Una - PE. Alves et al. (2013) mostraram que a distribuição da evapotranspiração e precipitação no evapopluviograma, geraram quatro faixas térmicas e os seis setores hídri$\cos$, sendo uma ferramenta eficaz na caracterização do clima de uma região para exploração de determinada cultura. Na figura 3 pode observa-se a existência de quatro tipos de clima predominante na área de estudo que são: clima Árido com três meses; clima seco com dois meses; clima subúmido com cinco meses e o clima úmido com dois meses. Estes índices estão de acordo com vários estudos realizados para o semiárido nordestino, (Medeiros et al., 2013 e Matos et al., 2014).

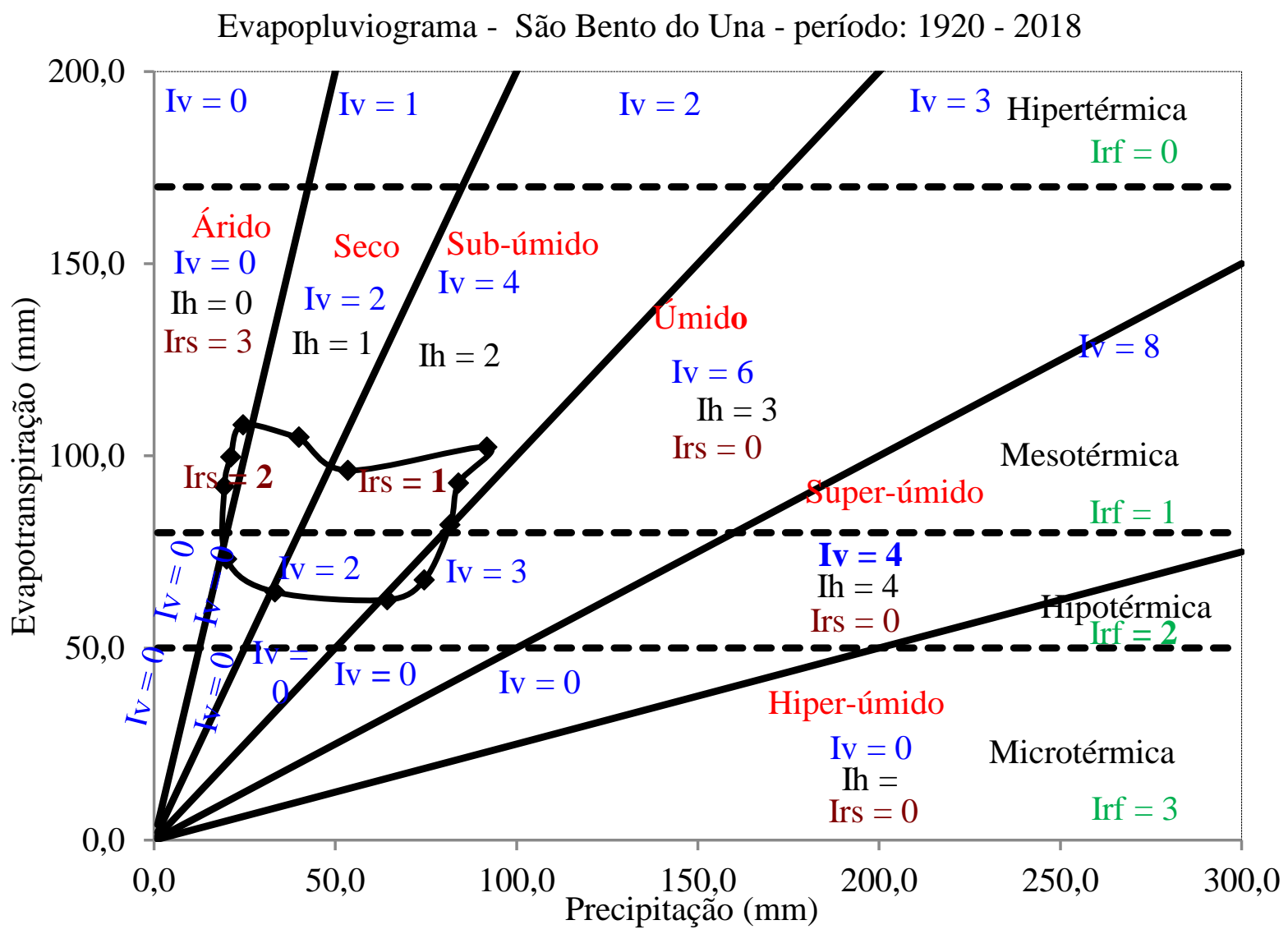

Figura 3 - Distribuição dos setores hídricos e faixas térmicas do evapopluviograma para o município do município de São Bento do Una - PE.

Medeiros (2018) mostrou que os indicadores climáticos lembram as condições para explorar as cultivares agrícolas de forma sustentável levando-se em conta um planejamento adequado de modo que se tenha retorno econômico, com base nas condições de clima e solo desta área e que alcance a máxima rentabilidade agrícola. 
Tabela 3 - Índices e parâmetros climáticos para o município São Bento do Una - PE.

\begin{tabular}{|c|c|c|c|c|c|c|c|c|c|c|}
\hline \multirow{2}{*}{$\begin{array}{c}\text { Índice } \\
\text { Climático }\end{array}$} & \multirow{2}{*}{ Ih } & \multirow{2}{*}{ Iv } & \multirow{2}{*}{$\mathrm{I}_{\mathrm{rs}}$} & \multirow{2}{*}{$\mathrm{I}_{\mathrm{rf}}$} & $\mathrm{Cv}$ & $\mathrm{T}_{\mathrm{a}}$ & $\mathrm{P}$ & ETp & DEF & EXC \\
\hline & & & & & $(\%)$ & $\left({ }^{\circ} \mathrm{C}\right)$ & \multicolumn{4}{|c|}{$(\mathrm{mm})$} \\
\hline Valor & 18 & 36 & 18 & 15 & 17,9 & 22,0 & 608,2 & $1.045,9$ & 437,6 & 0,0 \\
\hline
\end{tabular}

Legenda: $\mathrm{I}_{\mathrm{h}}$ - Índice hídrico anual proveniente do balanço hídrico, $\mathrm{I}_{\mathrm{v}}$ - Índice vegetativo anual, $\mathrm{I}_{\mathrm{rs}}$ - Índice de repouso por seca, $\mathrm{I}_{\mathrm{rf}}$ - Índice de repouso por frio, $\mathrm{Cv}$ - Concentração da evapotranspiração potencial na estação quente, T - Temperatura média anual, $\mathrm{P}$ - Precipitação, ETp - Evapotranspiração Potencial anual, DEF - Deficiência hídrica e EXC - Excesso hídrico.

A produção agrícola é uma atividade econômica que sofre influência das condições edafoclimáticas local, do meio físico e aspecto ecológico. Técnicas possibilitam a identificação de ambientes favoráveis à produção para diferentes variáveis agrícolas, uma vez que cada região possui várias sub-regiões com características de solo e clima distintos possuindo aptidões climáticas diferentes para cada tipo de cultivares (Gleriani, 2000). A determinação dos componentes do balanço hídrico permitiu um maior conhecimento da realidade climática da área estudada, ao mesmo tempo em que oferece condições de compatibilização entre a água retida no solo e as diferentes formas de utilização do mesmo, objetivando a minimização dos riscos para a cultura do sorgo.

\section{CONCLUSÕES}

A técnica de classificação e aptidões climática utilizando-se dos índices de deficiência e excedentes hídricos e dos índices pluviais para a área estudada aponta uma aptidão moderada para o plantio do sorgo.

Este plantio deverá ser realizado no período chuvoso, utilizando-se das técnicas do preparo do solo e o uso de irrigações suplementares quando exigidos.

Para evitar-se problema com umidade de solo e a plantação não sofre estresse hídrico ocasionado por períodos de veranicos prolongados deve-se escolher áreas de baixos para realizações do plantio.

Os índices térmicos e pluviais são favoráveis ao plantio de cerqueiro para a região, deve-se lembrar de que o município não tem água de subsolo, para tanto o plantio deverá ocorrer no período chuvoso e sua produção estocada.

O principal objetivo deste artigo é de demonstrar que as condições de tempo e clima são necessaria e suficientes para plantio do sorgo e mostar mais uma alternativa de alimentação para a avicultura da região.

\section{REFERÊNCIAS BIBLIOGRÁFICAS}

Alvares, CA; Stape, JL; Sentelhas, PC; Gonçalves, JLM; Sparovek, G. Köppen's climate classification map for Brazil. Meteorologische Zeitschrift, v.22, p.711-728. 2014.
Alves, J.M.B.; Souza, R.O.; Campos, J.N.B. Previsão da anomalia de Temperatura da Superfície do Mar (TSM) no Atlântico Tropical, com a equação da difusão de temperatura. Revista ClimAnálise, Instituto Nacional de Pesquisas Espaciais (INPE), São José dos Campos, SP, Ano 3, n.1, p.6-19. 2013.

APAC. Agência Pernambucana de água e clima. http//apac/meteorologia/dados. 2019.

Blain, G. Considerações estatísticas relativas à oito séries de precipitação pluvial da Secretaria de Agricultura e Abastecimento do Estado de São Paulo, Revista Brasileira de Meteorologia, 24, p.12-23. 2009.

Cavalcanti, EP; Silva, EDV. Estimativa da temperatura do ar em função das coordenadas locais. In: Congresso Brasileiro de Meteorologia, 8, 1994. Belo Horizonte, Anais..., Belo Horizonte: SBMET, v.1, p.154-157. 1994.

Cavalcanti, EP; Silva, VPR; Sousa, FAZ. Programa computacional para a estimativa da temperatura do ar para a região Nordeste do Brasil. Revista Brasileira de Engenharia Agrícola e Ambiental, v.10, n.1, p.140-147. 2006.

Desouzart, O. Futuro econômico da indústria avícola. Aveworld, Ed. 59, Ano 10. 2012.

EMBRAPA. Aptidão climática do Estado de Alagoas para culturas agrícolas. Relatório Técnico. Convênios SEAGRIAL/Embrapa Solos n.10200.04/0126-6 e 10200.09/0134-5. Recife: Embrapa Solos, 86p. 2012.

Ferreira, FS; Moreno, NBC; Evangelista, JSB; Silva, ACA; Amancio, LCS, A fruticultura no Ceará: evolução e tendências na região metropolitana do Cariri. Enciclopédia Biosfera, v.10, n.18; p.01-13, 2014.

Köppen, W. Grundriss der Klimakunde: Outline of climate science. Berlin: Walter de Gruyter. p.388. 1931.

Köppen, W; Geiger, R. Klimate der Erde. Gotha: Verlag Justus Perthes. Wall-map 150 x 200cm. 1928.

MAPA. Ministério da Agricultura, Pecuária e Abastecimento. Sistema Integrado de Legislação. BINAGRI SISLEGIS. Portaria 233/2014 de 24/11/2014. Disponível em: http://sistemasweb.agricultura.gov.br/sislegis/action/detalhaAto.do?method=visualizarAtoPortalMapa\&chave=304999056. Acesso em: 2020. 2014.

Matos, R.M.; Medeiros, R.M.; Silva, P.F.; Santos, D. Caracterização e aptidão climática de culturas para o município de Alhandra - PB, Brasil. Revista Brasileira de Agricultura Irrigada v.9, ${ }^{\circ} .3$, p.183-192, ISSN 1982-7679 (On-line). Fortaleza, CE, INOVAGRI, http://www.inovagri.org.br . DOI: 10.7127/rbai.v9n300288. 2015. 
Medeiros, RM. Milho e sorgo e suas potencialidades nas aptidões climáticas para o Estado da Paraíba, Brasil. Revista Mirante, Anápolis (GO), v. 13, n. 2, dez. 2020. ISSN 19814089

Medeiros, RM. Aptidão climática da cultura do caju na bacia hidrográfica do rio Ipojuca. Anais da Academia Pernambucana de Ciência Agronômica. v.15, p.20-40, 2018.

Medeiros, RM. Fatores provocadores e/ou inibidores de precipitações no estado do Pernambuco. 2016.

Medeiros, RM. Planilhas do Balanço Hídrico Normal segundo Thornthwaite e Mather (1955). s.n. 2016.

Medeiros, RM.; Duarte, JFM. Caju versus sorgo e sua aptidão climático no município de Recife - PE - Brasil. Revista Percurso - NEMO Maringá, v.12, n.1, p. 03-18, 2020. ISSN: $2177-3300$

Medeiros, RM; Holanda, RM; Viana, MA; Silva, VP. Climate classification in Köppen model for the state of Pernambuco - Brazil. Revista de Geografia (Recife). v.35, p.219-234, 2018.

Medeiros, RM; Matos, RM; Silva, PF; Silva, JA. Caracterização climática e diagnóstico da aptidão agroclimática de culturas para Barbalha - CE. Enciclopédia Biosfera, Centro Científico Conhecer - Goiânia, v.11 n.21; p. 2015

Medeiros, RM; Silva, JAS; Silva, O; Silva, A; Matos, RM; Balbino, DP. Balanço hídrico climatológico e classificação climática para a área produtora da banana do município de Barbalha, CE. Revista Brasileira de Agricultura Irrigada. v.7, $n^{\circ} .4$, p.258 - 268, ISSN 1982-7679 (On-line), Fortaleza, CE, INOVAGRI - http://www.inovagri.org.br, DOI: 10.7127/rbai.v7n400018.

Oliveira Neto, SN; Reis, GG; Reis, MGF; Leite, HG; Costa, JMN. Estimativa de temperaturas mínima, média e máxima do território brasileiro situado entre 16 e $24^{\circ}$ latitude sul e 48 e $60^{\circ}$ longitude oeste. Engenharia na Agricultura, Viçosa, MG, v.10, n.1-4, p.57-61, 2002.

Oliveira, JB. Análise pluviométrica e evapotranspiração de referência para dez localidades do estado do Ceará-Brasil. Areia: UFPB, CCA, (Trabalho de conclusão de curso de graduação). 1996.

Santos, GO; Hernandez, FBT.; Rossetti, JC. Balanço hídrico como ferramenta ao planejamento agropecuário para a região de Marinópolis, noroeste do estado de São Paulo. Revista Brasileira de Agricultura Irrigada, v.4, n.3, p.142-149, 2010.

Sousa, IF; Silva, VPR; Sabino, FG; Netto, AO; Silva, BKN; Azevedo, PV. Evapotranspiração de referência nos perímetros irrigados do estado de Sergipe. Revista Brasileira de Engenharia Agrícola e Ambiental, v.14, n.6, p.633-644, 1998.

Souza, AP. et al. Classificação climática e balanço hídrico climatológico no estado de Mato Grosso. Nativa, Sinop, v.1, n.1, p.34-43. 2015.

SUDENE - Superintendência de Desenvolvimento do Nordeste. Dados pluviométricos mensais do Nordeste - Piauí. Recife, 1990 (Série Pluviometria, 2).

Tabosa, JN; Reis, OV; Brito, ARMB; Monteiro, MCD; Simplício, JB; Oliveira, JAC; Silva, FG; Neto, ADA; Dias, FM; Lira, MA; Filho, JJT; Nascimento, MMA; Lima, LE;
Carvalho, HWL; Oliveira, LR. Comportamento de cultivares de sorgo forrageiro em diferentes ambientes agroecológicos dos Estados de Pernambuco e Alagoas. Revista Brasileira de Milho e Sorgo, p.47-58. 2002.

Thornthwaite, CW. An approach towards a rational classification of climate. Geographical Review, London, v.38, p.55-94, 1948.

Thornthwaite, CW; Mather, JR. The water balance. Publication in Climatology ${ }^{\circ} 8$, Laboratory of Climatology, Centerton, N.J. 1955.

Toledo, JV; Martins, LD; Klippel, VH; Pezzopane, JEM; Tomaz, MA; Amaral, JFT. Zoneamento agroclimático para a cultura do pinhão manso (Jatropha curcas L.) e da mamona (Ricinus communis L.) no estado do Espírito Santo. Agropecuária Científica no Semi-Árido, v.5, p.41-51, 2009.

Varejão-Silva, MA. Meteorologia e Climatologia. Versão Digital, Recife, 1984. p.516

Wollmann, CA; Galvani, E. Zoneamento agroclimático: linhas de pesquisa e caracterização teórica-conceitual. Sociedade e Natureza, v.25, p.179-190, 2013. 